\title{
Integration of technical universities into the learning networks of sustainable cities
}

\author{
M. Sotoudeh \& W. Peissl \\ Institute of Technology Assessment, Austrian Academy of Sciences, \\ Austria
}

\begin{abstract}
Technical universities are influenced by social values related to the need for technological development and education. In return they influence society through the generation of knowledge, educating engineers, and interaction with the local community and international organizations, as well as through consumption of natural resources and generation of waste and emissions. They influence cities in their neighbourhoods, even if they are sometimes not strongly socially integrated into them. This presentation will discuss the requirements for the integration of technical universities into cities from the perspective of sustainable development. The contribution will include a discussion of the role of technical universities for future technological development depending on the needs and requirements of society. The contribution includes three main functions of universities, namely teaching, research and management.
\end{abstract}

Keywords: cultural sustainability, participative methods, citizen visions, quality management of universities.

\section{Introduction}

Technical universities have different opportunities to follow strategies for sustainable development and to be integrated into sustainable cities. Two main streams could be based on cultural versus ecological sustainability:

Debates on technological advancement in sustainable development exhibit both technical and socio-economic dimensions. They lead to very different understandings of the role of engineering. Numerous interpretations of sustainable development exist which take into account different objects to be sustained by various means to achieve sustainability. 
In his book, Davison [1] argues against different interpretations of sustainable development and contests meanings of sustainability related to technological development. Considering the diverse moral and political backgrounds of discussions on sustainability, Davison differentiates between "cultural sustainability" and "ecological modernization". Ecological modernisation is linked to the post-war environmental crises and to the belief that technology can solve environmental problems through eco-efficiency. In the eco-efficiency concept, technical innovations are a means of resources management and energy efficiency, as well as of recycling, waste reduction and prevention of toxicity and other environmental hazards. Nevertheless, Davison claims, in his "discourse on cultural sustainability", that the cultural and moral policies and values are the basis for development and suggest a type of technological development that does not view technology as the main ingredient for progress.

Regarding technology as a means of sustainability in a framework of social and environmental preconditions implies new concepts for technical development. An example of this concept is given in the Fourteenth Session of the UN Commission on Sustainable Development (CSD-14), 01-12 May 2006 in New York. The Science \& Technology NGO Caucus Statement gives the participation of women and local communities as preconditions for the application of Science and Technology in achieving sustainable energy resources and services for the rural and peri-urban community [2].

The cultural dimension of sustainability therefore seeks improvement in the role of women in engineering, focuses on cleaner technologies in the research programmes of universities, aims for integration of technical universities into their local environments and promotes development of solutions with local resources, as well as looking for the cooperation of the universities with private and public learning networks. The discussion of all these needs is outside the scope of this presentation.

This contribution focuses on the specification of needs and the measures for integrating technical universities into the private and public learning networks in sustainable cities. The specification has been developed from the results of research from engineering conferences up to 2006, results of an explorative survey in 2006 described by Sotoudeh [3], a citizen consultation on visions of science, technology and innovation in 2009, as well as informal personal communications and the authors' own experiences.

Needs for participation in learning networks will be discussed in this paper with reference to the management of technical universities, education and research.

\section{Needs for special management strategies in learning networks}

University management should coordinate teaching and research activities and prepare an appropriate environment for the education of future engineers and for the social integration of the university at local and international level. The content of the courses, the experimental and practical part of the studies and the 
life in campus should make future engineers aware of their responsibilities in sustainable development.

Universities are expected to be integrated into learning networks with communication plays a key role in the success of the organisations in such networks. Examples include communication outside the universities through technology transfer agencies, [4] or "Forumsakademie" [5]. Technical universities should not only communicate with industry and engineering associations but also with public institutions and citizens. The short-term targets, as well as the future visions of society, should be identified continuously and considered in the design of teaching and research programmes (see example in this paper on the CIVISTI project).

Nevertheless, there is often the need for a trade off between diverse needs because of conflicts between the targets or lack of resources for implementing all measures. The task of target setting for organisations such as universities with diverse objectives and needs, the development of measures and the assessment of results are, therefore, not only sequential but they also have to be recursive, fig. 1 .
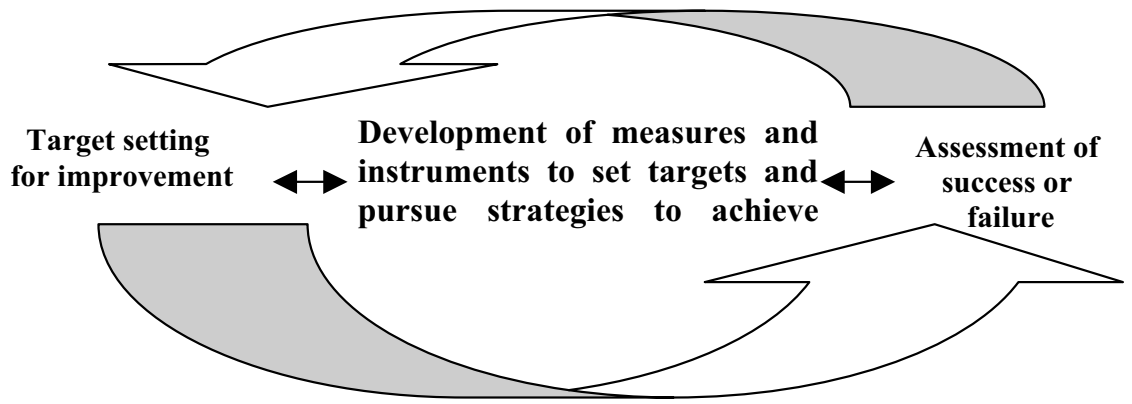

Figure 1: Relevant activity fields for the recursive decision-making process on objectives and measures.

This recursive process is integrated into the social development of the university and its environment. Measures for better communication with the environment cannot be developed in isolation at the university alone. The university management needs to consider the relevant internal and external conditions and to include the interests of all involved parties. The city administration should also be able to or be prepared to engage in an intensive and deep communication process with the university.

\subsection{How should management integrate universities into their local environment?}

Integration of technical universities into the local community has multiple purposes and characteristics.

A technical university using energy and material resources strongly influences the socio-economic condition of geographic areas far beyond its 
neighbourhood in the city. Some universities are integrated into the city in their neighbourhoods, give services to the local community and share their infrastructure with them. The universities in a sustainable development are integrated into the local community.

- physically through sharing resources; the university can also share streets and buildings with cities.

- organisationally by integrating with business, or sharing university laboratories with new SMEs (Small and Medium Enterprises) with innovative ideas, etc.

- deeply through social integration with the city and cooperation with offices of Local Agenda 21, etc.

Different mechanisms are often applied in the integration. If small companies have a "one room office" in the business department and use the university infrastructure for a certain period of time, it is a physical and organisational integration. This cooperation should be well organised, transparently declared and clearly defined through the university policies and approved by the responsible authorities. The university can also integrate part of a local technology park, where students can be involved in hands-on projects and be introduced to SMEs, and utilise the effects of synergy between it and the technology park.

The university laboratories can have versatile functions. It is important that they operate within strict environmental, human and animal-friendly regulations. They should take the necessary precautions to prevent, both inside and outside the laboratories, toxic emissions, cruel animal testing or tests with human health risks. Enforcement of such regulations provides selection and acceptance criteria for innovative small companies that are allowed to use the university infrastructure.

To integrate a university into a city it is necessary to control such undesirable effects and for the authorities responsible for the laboratories within the university to produce a transparent impact activities report.

Some universities have prepared policies that apply to all their research activities. The 2006 Research Compliance Handbook of the UC-Berkeley is an example of such a policy. This Handbook was intended to be an instructive guide for faculty and campus researchers. It has been designed to inform Berkeley campus faculty members (and other campus researchers) about key "research compliance" regulations mandated by the federal government and by the State of California that require oversight by the campus and additional activities on the part of the researcher [6].

\subsection{Integration of different interests}

A main challenge of the target setting for universities in sustainable development is the integration of different interests and the trade off between targets.

The integration of different interests can be achieved by different approaches such as project-oriented cooperation, flexible cooperation of individuals in 
special teams, establishment of interface-organisations such as LA21 Offices or participative methods.

Technical universities often apply project-oriented approaches for their research and education programmes. The project-oriented approach provides a good opportunity for cooperation with different participants or the consideration of interests of special groups in well-defined special projects. These projects could be selected through implementing comprehensive participative approaches.

The more flexible form of integration for different interests is cooperation among student associations and other representative groups at universities. In some universities students and staff with small children who may have periods at home are not isolated from the decision making at universities. They receive support to organise groups to discuss their ideas on the further development of the university during their maternity or paternity leave. Such "reflection teams" are also a valuable source for the initiation of new research activities [7].

Another kind of integration of people's interests can be realised through creation of an LA21 office. This office can contribute towards the local community needs assessment and transfer this information to the university's research and education programmes. The continuing education programme in particular can design student projects based on these needs.

An efficient way of integrating the society's interest is the use of research results of the relevant participative processes. A number of participatory research projects aim at foresight of relevant science and technology topics. An example that is presented in more detail in this contribution is the EU funded FP 7 project CIVISTI (Citizen Visions on Science, Technology and Innovation). In CIVISTI citizens from seven different European countries (Denmark, Austria, Flanders/Belgium, Finland, Malta, Bulgaria, Hungary) have an opportunity to define and communicate their visions of the future and transform these into relevant long-term science, technology and innovation issues. CIVISTI started in 2008 under the coordination of the Danish Board of Technology and will continue until February 2011 (www.civisti.org).

The CIVISTI project is based upon the idea that the process of defining relevant and proactive research agendas could in many respects gain from consultation of citizens. Social and technical developments generate at interface between science, technology and society. Linked to these developments, issues arise about societal management of the involved needs and uncertainties - for society as well as for the individual. The citizens are the carriers of the concerns and expectations to the future and, with the right facilitating methods, such concerns and expectations can be collected and transformed into relevant research agendas.

Identified needs from the first citizen consultations are combined in a catalogue of visions including 69 visions of the citizens from the seven European countries. The majority of identified visions deal with the social, cultural, ecological and economic context of technological development. A number of visions for 2050 relevant for technical universities and their role in sustainable cities are: 
Visions related to socio-cultural values for the improvement of the quality of life:

- Social innovations for the aging society,

- Educational innovations, such as multicultural education, for the improvement of tolerance, self-confidence and career chances,

- Cultural exchange.

Visions related to the bases of life: ecological and socio-economic factors for the improvement of life quality:

- Innovations for living situations in the cities and ecological life style,

- Sustainable production,

- A high number of environmental innovations for new energy production, provision of drinking water and green sustainable living,

- Knowledge and technological development for bringing generations together, reducing bureaucracy and developing smart environments.

The pre analysis of visions shows already that the message of the citizens is clear about the important role of education and technological development for a better quality of life.

In the framework of the CIVISTI-Project, these visions will be discussed in an expert and stakeholder workshop in April 2010 to identify relevant long-term research questions. The recommendations of the experts will be presented to the citizens and the results presented in a policy workshop to the decision-makers.

\subsection{Quality control of universities in sustainable development}

Sustainable development implies a continuous and comprehensive measurement at universities of success and failure of the measures for continuous quality improvement.

Siemer [8] presented the results of a survey, which shows sustainability indicator groups used by pioneer universities to be those based on:

- $\quad$ "the Triple Bottom Line (TBL) approach;

- an expanded environmental indicator set (expanded environmental reporting);

- $\quad$ standardized sustainability assessments, such as the Sustainable Pathways Toolkit (Good Company) and Campus Sustainability Assessment Framework (CSAF) as developed by Lindsay Cole. Sustainable Pathway Tools focus on 15 indicators on environmental management and health components. CSAF focuses on 175 indicators with ecological dimensions with supporting functions for the societal sphere.

- the Global Reporting Initiative (GRI) Guidelines.”

The latter one (GRI) is one of the first assessment concepts for universities. In 2001 the University of Florida developed performance indicators for the quality improvement of its environmental, economic, social, and education performance 
on the basis of GRI. These indicators can be used to mark the trends of the performance as positive, negative or neutral:

- Environmental Indicators

- Energy, Material, Water, Transport, Land Use/Biodiversity, Emissions, Effluents, and Waste - Waste Returned to Process (Recycling), Waste to Land, Effluents to Water;

- Economic Indicators

○ Revenues, Investments, Wages and Benefits, Community Development;

- Societal Indicators

○ Workplace, Health and Safety, Wages and Benefits, Training/ Education, Non-discrimination, Freedom of Association;

- $\quad$ Education Indicators

○ Faculty, Undergraduate Education, Graduate Education, Campus Safety.

"EESD Observatory" applies a new way of assessment. It is an initiative of a group of universities (Chalmers, the Technical University of Delft and the University of Barcelona) for assessment of integration of sustainable development principles in education, research and management of (technical) universities. EESD stands for Engineering Education in Sustainable Development. Its purpose is to "map the progress of and inspire activities within EESD in European higher education". The assessment includes the university's official policy on EESD for research, education and in-house activities, education - courses on SD at undergraduate and postgraduate level - embedding of SD in the curricula as well as the In-house Environmental Management System. The first report was published in 2006.

One barrier for all quality control measures has been the lack of enough time and personnel resources for the establishment of an integrated quality control system. The coordinated activity of a centre, which is independent from management of the university and is in contact with management, research and educational units, could be the means for effective quality management. This centre could coordinate the self-evaluation of the university units with external evaluation elements through stakeholders.

A coordination centre could also support the development of measures in the education and research of technical universities. In the next section we will present the results of a study between 2006 and 2008 on the needs for reform of technical education [3].

\section{Teaching and related educational objectives of technical universities in learning networks}

Technical education should provide the appropriate knowledge and skills as a base for a long engineering career (about 40 years). Curricula at technical schools have often been designed based on national needs for industry or governments. As a result of the massive changes of socio-economic conditions 
for engineering in global economic systems, and considering the huge environmental and social problems, there is a need for the reform of curricula of technical schools. Discussion of all the necessary changes is outside the scope of this contribution; only part of the required new skills is presented here.

An explorative survey was carried out in the period June-November 2006 gathering ideas from engineers with a wide spectrum of knowledge and engineering experience (electronics, building, surveying, mapping, construction, chemistry, computer, etc.) and from natural scientists with previous experiences at technical universities.

The survey questionnaire contained elements that universities usually use for their internal surveys (such as CEAS-UCB [9]) with additional questions relevant to the topic of engineering within sustainable development (such as the engagement of students during their education in international projects on environmental and social issues and local initiatives). Other topics discussed in mainstream engineering communities, such as common engineering education that was addressed in a project by the American National Academy of Engineering (see [10, 11]), were also covered.

The group of respondents included 44 individuals who were mostly engineers with diverse cultural and engineering backgrounds and different levels of experience in research, teaching, management and business. The respondent group included both international experts with a wide spectrum of activities, as well as engineers engaged in pure engineering tasks. Some respondents had worked on the development of concepts for engineering education in sustainable development. Respondents included women and men of different ages. Fourteen women and 30 men from different countries and backgrounds took part in the survey (more than 300 people were asked).

The results of the survey were compared in [3] with the proceedings of two different engineering conferences SEFI 2001 [12] and EESD 2006 [13] with different characteristics.

The results of the survey indicated a set of requirements for the education of engineers for:

- "Communication and presentation skills";

- "Management skills";

- "Basic engineering skills";

- "Cooperation skills";

- "IT skills";

- "Reflexive knowledge";

- "International experiences and language skills";

- "Practical knowledge gained from learning by doing";

- "Capability of thinking and acting beyond the borders of the company on global and local level";

- "Capability of critical thinking and taking responsibility".

Each category includes several issues identified by the respondents. Respondents claimed that the conventional basic engineering skills should be 
complementary to or integrated into the knowledge of the context of the engineering work.

The comparison between

- the SEFI 2001 conference as a conventional main stream engineering conference,

- the EESD 2006 conference with a strong focus on sustainable development and

- the results of the survey in [3] that include the opinions of different engineers with different focuses on sustainable development

showed that, in sustainable development, the curricula are required to be rich in courses and training for social, ethical, organisational and economic competences. The most important reason for the need for critical thinking is the complexity of problems. There is already experience with the content of new curricula for technical education and new programmes that are necessary for dealing with complex problems such as climate change, scarcity of fresh water, etc. (see [14-16]).

Not only the content of courses but also the learning methods have to be adequately designed. New methods of learning (e.g. E-learning, inter-cultural dialogue [17], adult education [18, 19]) have been intensively discussed by lecturers and educational experts. One of the key methods, which are important for technical universities in sustainable cities, is learning by doing and the participation of technical universities in problem-solving in their neighbourhoods.

\subsection{Education: learning by doing}

Engineers should be able to apply scientific knowledge while maintaining the capability to synthesise new knowledge for their special tasks. Technical universities' curricula in engineering need, therefore, to be rich with projects that combine thinking with doing.

In a version of learning by doing, engineering students are given research assignments to work on and solve in teams. They prepare project plans, formulate hypotheses, design experiments, document results and arrive at answers. They present their results before a jury, prepare a project report and respond to feedback from the jury [12]. Questions for engineering students could be real-life problems related to the local environment (e.g. in the city and its suburbs). There should also be issues related to visions and long-term strategies.

Learning by doing can also be split between different environments. It can be explained as out-of-campus experience. "Co-operative education is a rotation program, which alternates between industrial and academic work" [18].

Learning by doing is also a means of learning responsibility. Cooperation between technical universities and their neighbourhoods, and working in learning networks should be designed under shared responsibility. Active engagement for the identification of problems and design of research activities at local level and use of them in learning by doing education can be practised in many cases. 
The Institute for Urban \& Regional Development (IURD) at UC Berkeley has a special strategy for the identification of research questions and local engagement: IURD is an organized research unit that brings together faculty and students from across the campus to work on urban and regional development issues. IURD assists the campus community in raising research funds and provides administrative support for this work. IURD also supports graduate education through research training and internships for professional school students. IURD is a primary research home for many UC Berkeley faculties, primarily from the College of Environmental Design, but from other professional teaching programs as well. As a focal point on campus for faculty whose work engages current urban policy and planning issues, IURD brokers relationships with community partners and assists in the dissemination of community based research to wide audiences, in both academic and public venues. IURD has long served as a portal to the university for people in Bay Area communities, including city and county planners, community based organizations and others looking for technical assistance and guidance [6].

\subsection{Shared responsibility}

Engineers need to make decisions in difficult situations and take responsibility for the results of their decisions and the technical systems they develop. Van de Poel and Verbeek [21] give an overview of the discussion on shared responsibility, which includes external control and regulation, as well as individual responsibility. The practice of shared responsibility should start early at the university to prepare students for their involvement in real decisionmaking processes and projects. Although standard processes and regulations exist at universities that determine the responsibilities of the project staff, practice remains individually based on the specific understanding of the situation and is a special form of social integration.

It is part of shared responsibility to understand the interaction between cultural and technical development. This is required to be able to develop services for society with a deep understanding of cultural dimensions at local level while respecting the worldwide needs of human beings. Shared responsibility is especially important if technical universities cooperate with cities on new research topics.

\section{Conclusion}

Engineers are expected to be able to take different roles for design, management, development and implementation or service at technical facilities in different countries and regions of the world. Engineering education in sustainable development implies the potential to learn about local engagement and shared responsibility. The integration of technical universities in sustainable cities is therefore a precondition for achieving educational targets. It provides opportunities for problem-oriented experiences and training in skills to deal with 
communication with non-engineers and other skills, which go beyond technical factors.

Teaching and research activities in sustainable development are developed together and allow the social integration of the university at local and international level. The content of courses, the experimental and practical part of the study and the life in campus should make future engineers aware oft their responsibilities in sustainable development.

There are different mechanisms for the identification of long- and short-term requirements for education and research at technical universities. Technical universities, which are integrated in sustainable cities, need to identify and consider requirements of their neighbourhoods and be part of national and international learning networks.

The process of target setting, development of measures and evaluation of improvement of environmental, economic, social and educational performance of universities could be coordinated by an organisational unit. Such a unit is responsible for facilitating the integration of different interests in target setting by different approaches such as fixed and flexible project-oriented cooperation of stakeholders, the establishment of organisations such as LA21 Offices or participative methods.

\section{References}

[1] Davison, A., Technology and the Contested Meanings of Sustainability, New York: State University of New York Press, 2001.

[2] CSD-14, sustsci.aaas.org/files/CSD-14\%20Sci\%20\&\%20Tech $\% 20$ final $\%$ 20statement.doc

[3] Sotoudeh, M., Technical Education for Sustainability, an Analysis of Needs in the 21st Century, ed. W. L. Filho. 30 vols. Vol. 30, Environmental Education, Communication and Sustainability. Frankfurt am Main: Peter Lang Internationaler Verlag der Wissenschaften, 2009.

[4] Filho, W.L., European Reference Point for Technology Transfer for Sustainable Development: Mission and Projects. Proc. Of the Committing Universities to Sustainable Development, Graz, Austria, pp. 71-80, 2005.

[5] Narodoslawsky, M., Technical Universities as Platforms for the Societal Discourse About Sustainable Development - the Case of The "Forumakademie" At the Graz University of Technology. Proc. Of the EESD, Lyon, pp. 76, 2006.

[6] Berkeley, http://web.archive.org/web/20070816013502/ http://rac.berkeley.edu/compliancebook/introduction.html

[7] Philippi, T., Lebensphasen-Modelle Statt Rollenbilder, Von Beamer Durch Den Öffentlichen Und Privaten Raum. Österreich 2050, ed. H. Mahrer, pp. 43-56, 2005.

[8] Siemer, S., Elmer, S. and Rammel C., Pilot Study: Indicators of an Education for Sustainable Development. Environmental Protection umbrella Association Austria, Vienna, 2006. 
[9] CEAS-UCB. Questionnaire: What Do You Think Are the Most Important Skills for the Engineer of 2020? College of Engineering and Applied Science, University ofColorado at Boulder, http://engineering.colorado.edu /overview/EAC_Eng2020_Questionnaire.doc

[10] Clough, W. The Engineer of 2020 Project, a High Risk, High-Pay-Off Approach for the Future of U.S. Engineering Education. 2005.

[11] NAE., The Engineer of 2020, Project Prospectus. Washington: National Academy of Engineering, Committee on Engineering Education, 2005.

[12] Graaff, E., Thijs, W. and Wieringa P., Research as Learning Paradigm. Proc. of the New Engineering Competencies, Changing the Paradigm!, Copenhagen, 2001.

[13] Subai, C., Ferrer-Balas, D., Mulder, K.F. and Moszkowicz. P., Engineering Education in Sustainable Development. Proc. Of the EESD 2006, Lyon, 4-6 October, 2006.

[14] Mulder, K., Don't Preach. Practice!. Proc. Of the EESD 2006, Lyon, 4-6 October, pp. 49, 2006.

[15] Bootsma, M.C. and Driessen P.P.J., Exploring a Sustainable World. Proc. of the Committing Universities to Sustainable Development, Graz, Austria, pp. 431-443, 2005.

[16] Jischa, M. F., Ingenieurwissenschaften, Studium Der Umweltwissenschaften, ed. by E. Brandt, Springer-Verlag: Berlin, 2004.

[17] van Dam-Mieras, R., A Master Sustainable Development Based on the Richness of Diversity. Proc. of the EESD 2006, Lyon, pp. 14, 2006.

[18] Stöglehner, G., Mitter, H. and Jungmeier P., Adult Education as a Key Factor of Sustainable Rural Development. Proc. of the EESD 2006, Lyon, pp. 16, 2006.

[19] Del Corso, J.P., Fkephaliacos, C. and Merri. M., Concepts and Environmental Issues Applied to Economics and Management in the Higher Technician Courses of Agricultural Education." Proc. of the EESD 2006, pp. 18, Lyon 2006.

[20] El-Sayed, J., Industrial-Academic Integration Takes Learning out of the Classroom. Proc. of the New engineering competencies, changing the paradigm!, Copenhagen, 2001.

[21] van de Poel, I. and Verbeek P.P, (eds). Ethics and Engineering Design. Vol. 31, Science, Technology, \& Human Values, pp. 223, 2006. 